Georgia State University

ScholarWorks @ Georgia State University

$12-2-2015$

\title{
The Puzzling Fixity of Multiple Job Holding across Regions and Labor Markets
}

Barry T. Hirsch

Georgia State University, bhirsch@gsu.edu

Muhammad M. Husain

Georgia State University, mhusain1@gsu.edu

John V. Winters

Oklahoma State University, jvwinte@okstate.edu

Follow this and additional works at: https://scholarworks.gsu.edu/uwrg_workingpapers

\section{Recommended Citation}

Hirsch, Barry T.; Husain, Muhammad M.; and Winters, John V., "The Puzzling Fixity of Multiple Job Holding across Regions and Labor Markets" (2015). UWRG Working Papers. 147.

https://scholarworks.gsu.edu/uwrg_workingpapers/147

This Article is brought to you for free and open access by the Usery Workplace Research Group at ScholarWorks @ Georgia State University. It has been accepted for inclusion in UWRG Working Papers by an authorized administrator of ScholarWorks @ Georgia State University. For more information, please contact scholarworks@gsu.edu. 


\section{W. J. Usery Workplace Research Group Paper Series}

Working Paper 2015-12-2

December 2015

\section{The Puzzling Fixity of Multiple Job Holding across Regions and Labor Markets}

Barry T. Hirsch

Georgia State University and IZA

Muhammad M. Husain

Georgia State University

John V. Winters

Oklahoma State University and IZA 


\title{
The Puzzling Fixity of Multiple Job Holding across Regions and Labor Markets
}

\author{
Barry T. Hirsch, Muhammad M. Husain, and John V. Winters
}

December 2015

\begin{abstract}
Multiple job holding rates differ substantially across U.S. regions, states, and metropolitan areas. Rates decrease markedly with respect to labor market size. These patterns have been largely overlooked, despite being relatively fixed over (at least) the 1998-2014 period. This paper explores explanations for these persistent differences. We account for over half of the mean absolute deviation in multiple job holding across local labor markets (MSAs). Most important in explaining variation in multiple job holding are worker characteristics, commute times, MSA ancestry shares, and, to a lesser extent, labor market churn. City size accounts for little of the variation once we condition on commute times.
\end{abstract}

Keywords: Multiple job holding, local labor markets, city size and regional differences, commuting costs

JEL code: J21 (labor force and employment), R23 (regional labor markets)

Hirsch [contact author]: Department of Economics, Andrew Young School of Policy Studies, Georgia State University, Atlanta, Georgia 30302-3992, and IZA (Bonn). Email: bhirsch@gsu.edu.

Husain: Department of Economics, Andrew Young School of Policy Studies, Georgia State University, Atlanta, Georgia 30302-3992, Email: mhusain1 @ gsu.edu.

Winters: Department of Economics, Oklahoma State University, Stillwater, OK 74078-4011, and IZA (Bonn). Email: jwinte@okstate.edu. 


\section{Introduction}

Multiple job holding rates differ substantially across regions of the U.S., and these differences have been persistent over time. Multiple job holding is far more prevalent in Western North Central, Mountain, Northwest, and New England states than among states in other regions. Rates are lowest in the South. A similar pattern exists across metropolitan areas. Moreover, multiple job holding is substantially higher in non-urban areas than in metropolitan area labor markets. These geographic differences in multiple job holding rates are not widely recognized and have received minimal attention in the academic literature. ${ }^{1}$

The goal of this paper is two-fold. First we identify regional, labor market, and market size patterns in multiple job holding and show that these have been relatively stable over time. Second, we attempt to explain these systematic long-run differences in multiple job holding. In what follows, we first examine the pattern of labor market differences in multiple job holding and the extent to which these differences can and cannot be explained by standard worker and job measures. We then turn to other potential explanations for labor market variation in multiple job holding, including commuting times, worker ancestry, employment growth, and labor market churn. We fail to discover a magic set of covariates that fully accounts for these differences, but a substantive share of the cross-market variation is explained. The exercise is informative and increases our understanding both of multiple job holding and differences across local labor markets.

\section{Reasons for multiple job holding}

A primary job is generally defined as the job at which an individual works the most hours, with a second (or additional) job having fewer hours. Explanations for multiple jobs generally fall into one of two broad categories, resulting either from "hour constraints" or to obtain a preferred "job portfolio." Hour constraints on either a primary or secondary job can explain multiple job holding. If a worker's principal job has the higher wage but constrained work hours, some workers will increase utility by taking a lower paying second job (Shishko and Rostkers 1976). Workers not facing hour constraints on the primary job might take a higher paying second job that has constrained hours; say, a temporary job or one with limited hours per week. Unlike jobs with hourly pay, salaried jobs do not have explicit hour constraints, but do have an "earnings constraint" that can work in a similar way, leading some salaried workers to take a second job in order to increase their earnings. ${ }^{2}$

We adopt the phrase "job portfolio" from Renna and Oaxaca (2006), who develop a model of multiple job holding based on personal preferences for job differentiation. We include several explanations

\footnotetext{
${ }^{1}$ Using state level data, Partridge (2002) examines how multiple job holding varies across states and time, concluding that state differences are maintained over time. The geographic fixity of state multiple job holding over time is readily evident if one compares across years BLS annual reports on multiple job holding (e.g., U.S. BLS 2015).

${ }^{2}$ Hirsch et al. (2015) make this point. They find a multiple job holding rate for salaried workers that is about half a percentage point lower than for hourly workers.
} 
for multiple job holding under this category. First, workers may prefer diversity in job tasks, being happier dividing time in two different jobs or occupations. Second, workers may work in a second job as a form of insurance, say diversifying one's human capital or because of employment or income uncertainty in a first job. Third, workers wanting to switch occupations or employers due to a poor match can use a second job to obtain on-the-job training that might facilitate a utility-enhancing move (for evidence on skill diversification, see Panos et al. (2014)). Fourth, workers may take a second job because of temporary financial or family circumstances, expecting that their preferred long-run match is a single primary job.

Hipple (2010) provides extensive descriptive evidence (means) on multiple job holding rates for various groups of workers using the CPS. Hirsch et al. (2015) do likewise (Table 3), while also providing estimates of conditional effects on multiple job holding for a rich set of worker, job, and location attributes (Hirsch et al. 2015, Appendix Table A-1). Lalé (2015) provides additional descriptive evidence showing that falling multiple job holding rates over time primarily reflect declining monthly transitions from single-job to multiple-job holding. In addition to use of the CPS, analyses of multiple job holding have primarily used the Survey of Income and Program Participation (SIPP), the Panel Study of Income Dynamics (PSID), and the 1979 National Longitudinal Survey of Youth (NLSY). ${ }^{3}$ These longitudinal data sets enable researchers to examine worker transitions into and out of multiple job holding over time and provide a rich set of covariates. Because of its large size and geographic coverage, the CPS is better suited to examine multiple job holding patterns across labor markets than these alternative data sets.

\section{Measurement of multiple job holding using the Current Population Survey (CPS)}

The Current Population Survey (CPS) began regularly collecting information on multiple job holding in 1994 as part of the survey's major redesign. Prior to 1994, occasional CPS supplements included information on multiple job holding. All employed individuals are asked the question: "Last week, did you have more than one job (or business), including part-time, evening, or weekend work?" If they answer "yes," they are then asked how many jobs (or businesses) they had altogether and how many hours they worked each week at all their jobs. The primary job is defined as the one at which the greatest number of hours were worked. Using monthly CPS data, the U.S. Bureau of Labor Statistics (BLS) defines a multiple job holder as an individual who: (a) holds wage and salary jobs with two or more employers; (b) combines a wage and salary job with self-employment; or (c) combines a wage and salary job with one as an unpaid family worker. In our analysis, multiple job holding is defined similarly, with the exception that our sample includes only those workers whose primary job is a wage and salary job because earnings (and other) information is not provided for self-employment jobs (the March supplement provides such information for the previous

\footnotetext{
${ }^{3}$ Conway and Kimmel (1998, 2001) and Krishnan (1990) use SIPP; Paxson and Sicherman (1996) use the PSID, and Amuédo-Dorantes and Kimmel (2009) use the NLSY79.
} 
calendar year).

In this paper, we utilize the Current Population Survey (CPS) Monthly Outgoing Rotation Group (CPS-ORG) data files from January 1998 through December 2014. The CPS-ORG includes the quarter sample of each month's survey who provide information on usual weekly earnings and hours worked on the primary job among wage and salary workers, as well as other information not asked of all rotation groups (e.g., union status). In addition to the added labor market information, use of the CPS-ORG insures that each worker is included only once within a calendar year. ${ }^{4}$ Note that the CPS provides information on usual weekly earnings (and the straight-time wage for hourly workers) only for workers' primary wage and salary jobs and not for second jobs. The CPS does report work hours, class of workers (private for-profit, private not-for-profit, federal, state, or local), detailed occupation, and detailed industry for both the primary and second job.

Our CPS "urban" sample includes 1,964,059 non-student wage and salary workers (on their primary job), ages 18-65, for 1998 through 2014, located in 259 MSAs throughout the U.S. This urban sample accounts for about three-fourths of the U.S. workforce. ${ }^{5}$ In addition, we provide more limited analysis using a "non-urban" sample of 690,688 who live outside these designated MSAs, leading to an overall U.S. sample of 2,654,747. The overall weighted multiple job holding rate over 1998-2014 for the national sample is 5.0 percent. Focus on the national sample masks the substantially higher rates of multiple job holding (MJH) in non-urban as compared to urban areas. As compared to the mean MJH rate of 4.7 percent for the large urban sample, the MJH rate in the non-urban area is 6.0 percent. As we show subsequently, MJH rates fall systematically with respect to labor market size, even when conditioned on covariates. Our large CPS national sample of workers over multiple years enables us to reliably examine differences in multiple job holding across U.S. labor markets.

Figure 1 provides national evidence on the trends over time in multiple job holding. Annual rates have trended down over time, from 5.8 percent in 1998 to 4.4 percent in 2014. Not shown in Figure 1 is the fact that this downward trend has been stronger among men than among women. Men's MJH rates between 1994 and 2014 declined from 5.9 to 4.1 percent, whereas women's rates fell from 5.8 to 4.7 percent. $^{6}$ The

\footnotetext{
${ }^{4}$ Households are in the survey for a total of eight months: they are interviewed for four consecutive months (rotation groups 1-4), then out of the survey the next eight months, and then reenter the survey the following four months (rotation groups 5-8).

${ }^{5}$ The CPS does not identify all MSAs (now named CBSAs), typically excluding those that are small (roughly below 100,000 in size). Every 10 years Census removes and adds smaller MSAs based on population changes. What we refer to as our "non-urban" group includes both workers living outside of an MSA, plus those in small MSAs not identified in the CPS over the full 1998-2014 period. Of the 259 MSAs, 202 are included in our sample for all years.

${ }^{6}$ Our MJH rates are slightly lower than official BLS rates. There are two differences between BLS and our measure of MJH. First, our sample is based on the outgoing rotation groups rather than the full CPS. Using the quarter sample ORGs provides us with workers' earnings in their primary job and insures that our sample includes each worker only once within a given year. Hall (1970) and Krueger et al. (2014) find somewhat higher unemployment rates in the first
} 
sharper decline among men than women occurs in both the metropolitan and non-metropolitan samples. The secular downward trend cannot be accounted for by macroeconomic conditions. Multiple job holding is weakly cyclical, but the relationship is close enough to zero to characterize it as acyclic (Hirsch et al. 2015). ${ }^{7}$ Of interest for our analysis is the not widely known difference in rates between those in non-urban versus metropolitan areas, as seen in Figure 1.

In order to enhance reliability of population estimates, the CPS "oversamples" households in less populated markets and "undersamples" in large markets. Because MJH rates systematically decline with respect to size, it is essential that we use Census survey weights to provide unbiased descriptive statistics for representative populations. Because multiple job holding behavior may be heterogeneous, weighted regressions provide coefficient estimates representing roughly average effects across heterogeneous groups (see Solon et al. 2015).

Unless otherwise stated, all analyses in the paper use survey weights. To illustrate the difference weighting has on descriptive statistics, it is useful to compare weighted and unweighted mean multiple job holding rates. As stated above, over the 1998-2014 period the national, urban, and non-urban weighted mean $\mathrm{MJH}$ rates are 5.0, 4.7, and 6.0 percent. The comparable non-weighted sample means are 5.5, 5.0, and 6.9 percent.

\section{Systematic differences in multiple job holding across regions, states, and metropolitan areas}

Multiple job holding rates differ substantially across regions, states, and labor markets. Moreover, these differences have substantial fixity over time. Neither the geographic differences in multiple job holding nor the stability of these differences over time is widely recognized. In this section, we provide descriptive evidence on each of these patterns. We first use our 1998-2014 CPS data set to show regional and state differences in multiple job holding over time. We then examine evidence on multiple job holding differences across non-urban versus urban areas and show how multiple job holding decreases with metropolitan area size. Multiple job holding differences across metropolitan areas display the same regional pattern seen for states. The stability of state multiple job holding is shown through comparisons of MJH rates and relative

and fifth rotation groups compared to the second through fourth and sixth through eight. Second, BLS includes as multiple job holders those whose primary job is self-employment if they have a second job that is wage and salary (BLS excludes workers with multiple businesses but no wage and salary job). We exclude workers whose primary job is selfemployment since earnings is not provided for these workers.

${ }^{7}$ Theory is ambiguous. Labor supply for multiple jobs is potentially countercyclical if income effects are strong, but during recessions demand is low and one cannot assume market clearing. Hirsch et al. (2015) examine determinants of individual multiple job holding and find small (but statistically significant) negative coefficients on the unemployment rate absent MSA fixed effects. These estimates effectively go to zero once MSA fixed effects are added. Using short CPS panels, they find no relationship between within-labor market changes in unemployment and individual worker transitions between single and multiple job holding. 
rankings in 2013-2014 versus 1998-1999. A similar analysis is shown for metropolitan areas based on MJH rates in 2012-2014 versus 1998-2000. Following presentation of the descriptive evidence, we discuss and analyze potential explanations for these long-standing differences in multiple job holding.

Figure 2 provides color-coded maps of relative multiple job holding rates among U.S. states in 199899 versus 2013-14. Given the downward trend in MJH rates over time, we grouped the states into quartiles, with states with the highest MJH rates coded in dark blue, the next quartile in turquoise, the next in grey, and the lowest in cream. Readily evident is the substantial similarity of the color codes over time, with blocks of blue (high $\mathrm{MJH}$ ) among states in the north central region and northern New England, and blocks of cream (low MJH) in the southeast, southwest, California, Nevada, New York, and New Jersey. In the top half of Figure 3, we show the scatterplot between the 51 state rankings (including D.C.) in 2013-14 (y-axis) versus the rankings 15 years later in 1998-99 (x-axis). The same pattern is seen in the bottom half of Figure 3, where the scatterplot is based on 1998-99 and 2013-14 multiple job holding rates rather than ranks. Rankings in multiple job holding are closely related over the time period. An OLS regressions of 2013-14 MJH state ranking on 1998-99 rank had an $\mathrm{R}^{2}$ of 0.75 and produced a coefficient of 0.73 on the 1998-99 rank. A similar regression using $\mathrm{MJH}$ rates (rather than rank) had an $\mathrm{R}^{2}$ of 0.73 and a coefficient of 0.66 on the 1998-99 rate.

The principal analysis in this paper focuses on multiple job holding across urban labor markets, based on metropolitan areas identified in the CPS. Evident here are not only regional differences similar to that seen above for states, but also differences by market size. We offer several pieces of evidence. Tables 1a and $1 \mathrm{~b}$ provide lists of MSAs with the highest and lowest levels of multiple job holding averaged over the entire 1998-2014 period (here we include only metropolitan areas that were among the 202 MSAs included in the CPS over the entire period). Here we see regional patterns similar to that seen in the state maps, with mostly southern cities, a few California cities, and the large NYC-NJ MSA having low multiple job holding rates, while relatively high rates are observed for north central MSAs, several of which are home to large universities. In order to examine fixity in multiple job holding over time, in Figure 4 we show a scatterplot similar to that seen previously for states. The horizontal axis measures the MSA multiple job holding rates calculated for 1998-2001 while the vertical axis shows the rates for 2011-2014. Four-year averages are used to reduce sampling error, a concern for smaller cities. As evident in the figure, there is a relatively high degree of similarity in relative rates between the years. A weighted OLS regression of the 2011-14 rate on the 1998-2001 rate produced an $\mathrm{R}^{2}$ of 0.37 and a coefficient of 0.59 on the $1998-2001$ rate.

In addition to there being regional patterns and a considerable degree of fixity over time, multiple job holding also varies with respect to market size. In Table 2, we show the average multiple job holding rate over the entire 1998-2014 period for both non-urban areas and for metropolitan areas of varying sizes. In column 1, we show the mean multiple job holding rates among workers residing in non-urban areas; that is, 
those areas of the country that are either outside of an MSA or in a small MSA (typically less than a 100,000 population and not identified in the CPS), plus six groups of MSAs with increasing populations.

The mean (weighted) MJH rates over 1998-2014 systematically decline with size, ranging from 6.0 percent for the non-urban areas down to 3.9 percent among workers in MSAs 5 million plus. Little of the difference by size can be accounted for by standard covariates. Adding a detailed set of worker and job attributes (listed in the note to Table 2), the spread between the unadjusted non-urban and largest urban markets decreases only slightly, from 2.1 to 1.9 percent (columns 1 versus 2). Adding in eight regional dummies in column (3) to account for the nine Census regions reduces the difference in MJH rates to 1.5 percent, with similar differences now seen for workers in metro areas with populations between 2.5 and 5.0 million and those 5.0 million and over. MJH rates for these large urban markets remain substantially lower than among less-populated labor markets.

\section{What might explain metropolitan area differences in multiple job holding?}

The discussion and evidence in the prior section established that there is considerable variation across U.S. labor markets in rates of multiple job holding and that these differences are relatively stable over time. The obvious question that arises from such evidence is: What explains these labor market differences in multiple job holding? We consider several possible explanations below, some that can be measured directly, some that can be imperfectly captured through proxy measures, and some that cannot be readily measured. Our strategy is to begin with the "raw" differences in multiple job holding rates for our 259 metro labor markets, and then see to what extent these differences (measured by the mean absolute deviation in rates) are reduced as we introduce various covariates.

The CPS contains reasonably detailed measures of individual worker demographics and job types. So a reasonable place to begin is to control first for differences in worker demographics and human capital (the latter measured by schooling and potential experience). We then add measures of job attributes on the primary job (earnings, industry, occupation, and union status), followed by the addition of controls for labor market size. What will be seen is that such controls account for a non-trivial amount of the dispersion in multiple job holding across markets, but most of the variation remains unexplained. We then turn to possible explanations not directly measured in the CPS. These include differences in local labor market employment growth rates, differences in labor market churn (turnover), differences in commuting costs across labor markets, and different cultural attitudes toward work (proxied by ancestry) not fully reflected in standard demographic measures.

As discussed at the outset, the principal economic-based explanation for multiple job holding is that it results from hours constraints. A plausible conjecture is that such hours constraints might be more likely in labor markets with slow rates of labor demand and employment growth, while being less constrained in high 
growth labor markets. Of course, we cannot easily distinguish between employment growth driven by labor demand versus labor supply. A cursory comparison of MSAs and states with high versus low multiple job holding rates suggests that average multiple job holding is somewhat higher in markets with lower long-run employment growth, but the relationship is weak.

A second possible explanation for residual differences in labor market multiple job holding is the degree of labor market churn or dynamism, although theory here is not unambiguous. Recent literature has noted that the U.S. is exhibiting a gradual decline in overall labor market turnover, possibly reflecting a lower degree of dynamism in the U.S. economy (Decker et al., 2014). Similar patterns and concerns have been noted with respect to worker mobility. Internal migration within the U.S. has shown a gradual but steady decline since the early 1980s, raising further concerns that labor mobility and economic dynamism have fallen (Molloy et al. 2011, 2014).

A typical argument is that high (but not too high) rates of turnover reflect and make possible desirable matching and sorting in the labor market. If that is the case, we would expect high rates of churn to be associated with good primary job matches in which hours are not constrained, and thus lower rates of multiple job holding. That said, one can argue for a relationship in the opposite direction. Hyatt and Spletzer (2013) find that secular employment losses are associated with fewer short-term (one-quarter) jobs. Elsewhere, it is suggested that multiple job holding may be similar in some ways to short-term jobs (Abraham et al. 2013). If this is correct, the recent gradual decline in multiple-job holding could be associated with lower churn and fewer short-term jobs. As noted by Abraham et al. (2013), there are substantial differences in measuring multiple job holding based on household (CPS) versus using establishment data. Using data matching individual worker information with administrative employerreported data indicated that establishment measures of multiple jobs within the same quarter often do not coincide with CPS worker reports of multiple job holding. Likewise, CPS reports of multiple job holding do not always show up in administrative payroll records as two jobs within the same quarter. In the analysis that follows, we examine whether MJH rates are related to the level of churn. Rates of turnover at the MSA (and state) levels are constructed from the full 1998-2014 CPS files (i.e., all rotation groups) based on individual monthly individual transitions between employment and non-employment and job changes among those employed in consecutive months.

A third possible explanation for MSA variation in multiple job holding is that low commuting costs in a labor market will be associated with higher MJH rates, and vice-versa. This is a natural extension of the work by Black et al. (2014), who find that metropolitan areas such as Minneapolis, with low rates of traffic congestion, have higher rates of female labor force participation than do more congested labor markets (e.g., the New York metro area) with long commute times. A quick glance at state rates of multiple job holding 
show Minnesota (and surrounding states) with among the highest multiple job holding rates, while New York has a relatively low rate multiple job holding rate as compared to other northern states. The New York MSA is one of the few non-southern metro areas in the list of MSAs with low multiple job holding.

Multiple job holding decisions could be particularly sensitive to congestion costs. Because commuting is largely a fixed cost and hours worked at second jobs are substantially lower than in primary jobs, the relative costs of congestion are high in second jobs. Black et al. (2014) find that married women are particularly sensitive to high commute costs. Using similar logic, we might expect female multiple job holding to be more sensitive to commute costs than is male multiple job holding. Census data for 2000 and, for later years, the American Community Survey (ACS), provide data on commute times (as well as transportation mode and number of vehicles). Given that city size is inversely related to multiple job holding, it is likely that commute times should explain some portion of the residual differences in multiple job holding across labor markets.

The high rates of multiple job holding in the north central states give rise to a fourth possible explanation for systematic regional differences. Ethnic, religious, and cultural differences may affect labor market outcomes, including multiple job holding. The north central region of the U.S. has a large number of households who are Lutheran and/or of German and Scandinavian heritage. Data on religion by area is not provided by Census or other governmental statistical agencies. The CPS, which provides data on multiple job holding, includes little information on ethnicity, apart from identifying those who are Hispanic, and provides no information on ancestry other than country of origin among those who are foreign born. Data on ancestry, however, is available in the decennial census long form survey in 2000 and the American Community Survey (ACS). We compile metro area measures of ancestry combining the 2000 Census with the pooled 2005-2011 ACS. These measures allow us to demonstrate whether ancestry differences across U.S. labor markets are correlated with long-run differences in multiple job holding.

\section{Evidence on multiple job holding differences across labor markets}

In this section, we examine why multiple job holding differs across markets, with a focus on the explanations offered in the previous section. Our principle approach is to examine the extent to which controlling for a variety of detailed worker, job, and city size attributes can account for labor market differences in multiple job holding.

To describe the magnitude of MSA differences in multiple job holding, we measure the mean absolute deviation of MSA mean residuals estimated from individual level multiple job holding equations for 1998-2014. We move from an equation with minimal controls to those with increasingly detailed controls. Table 3 shows the weighted mean absolute deviation (MAD) using eleven specifications of a multiple job holding equation. Each specification sequentially adds variables (or groups of variables) and we then 
examine the extent to which MAD changes. Of course, the contribution of each variable(s) to the measure of dispersion is not independent of the order in which variables are entered. We have examined multiple orderings and the importance of most variables is relatively insensitive to the order in which they are entered. Our conclusion as to which factors are and are not important is based not only on the results shown in Table 3 , but also on results (not shown) using alternative orderings.

The first specification in Table 3 includes only year and month dummies, thus representing a measure of the dispersion in "unconditioned" average MJH rates across labor markets. The second specification adds control for worker demographic characteristics - sex, race/ethnicity, foreign-born, marital status, presence of young children, age, and education dummies. The third adds job-level controls measuring union status, class of worker, wages and hours worked on the primary job, and the fourth adds workers' broad occupation and industry. The fifth specification adds MSA commute times, the sixth adds city size dummies, and the seventh adds MSA mean earnings, housing values, and rental rates. The eighth specification adds MSA measures of ancestry, the ninth regional dummies, the tenth log employment growth between 1998 and 2014, and the eleventh a measure of average labor market turnover (churn) across all years.

As seen in Table 3, line 1, the weighted mean absolute deviation of MSA multiple job holding absent controls (apart from year and month dummies) is 0.96, an approximate 1 percentage point average absolute difference between MSA rates and the mean rate of multiple job holding. This average deviation from the mean is roughly a fifth of the size of the 5.0 percent mean level of multiple job holding. The second specification, which adds control for worker demographic characteristics, reduces MAD from 0.96 to 0.79. The third, which adds job-level controls measuring union status, public vs. private sector, a set of hours worked dummies, and the log wage on the primary job, reduces MAD from 0.79 to 0.74 . Addition of occupation and industry dummies of the primary job in model 4 slightly increases MAD. In short, accounting for individual worker and job measures available in the CPS, we can account for a rather modest amount of the dispersion in multiple job holding across markets, with MAD being reduced from 0.96 to 0.75 .

Beginning with model 5, we introduce variables that are measured at the MSA rather than individual level. The fifth specification adds MSA mean commute times (average minutes for a one-way trip from home to work), calculated from the pooled 2000 Census 5\% PUMS and 2005-2011 ACS for those persons who work outside the home. Inclusion of this measure sharply reduces unexplained deviations in multiple job holding, with MAD falling from 0.75 in line 4 to 0.63 in line 5 . In line 6, we add city size dummies, which have no discernable effect on MAD (it remains at 0.63 ). Of course, commute times and city size are highly correlated. When we reverse the order in which we introduce these two measures (not shown in Table 3), we find that adding city size dummies to line 4 reduces MAD from 0.75 to 0.69 ; further addition of commute 
times reduces it to 0.63 . Our conclusion from these results is that commute times play a major role in determining multiple job holding rates, as one would expect from theory. City size per se appears to have little effect once one controls for commute times. Indeed, despite our large sample size, none of the city size dummies is statistically significant at standard levels in the MJH regression with commute times included.

Our negative coefficients on commute times are highly similar in regressions with and without the city dummies. Across a wide range of specifications, the coefficient on mean transportation times for a daily commute (in minutes) is about -0.1 . This implies that for a 5 minute increase in a labor market's average commute time from home to work (the standard deviation across MSAs is 4.3 minutes), its MJH rate is lower by about 0.5 or half a percentage point. When we estimate separate $\mathrm{MJH}$ regressions for women and men, we find minimal differences in their sensitivity to average MSA commute times.

In model 7, we introduce three measures reflecting metro area income and housing values (costs) the mean hourly wage (holding constant individual worker wages), mean housing values, and mean rental values. Each of these measures is compiled from the 2000 Census and the ACS. These variables account for a small degree of market dispersion in multiple job holding, reducing MAD from 0.63 to 0.615 .

The regional patterns seen in state multiple job holding rates (Figure 2) prompted us to examine the effects of ancestry, as measured in the 2000 Census and annual ACS. Individuals are asked "What is your ancestry or ethnic origin?" This is followed by examples such as Italian, Jamaican, African American, Ukrainian, and so forth. Census codes up to two answers for an individual. They do not provide codes for answers that are rare. We use responses on first ancestry (and ignore second measures) and tabulate and include in our MJH regression the percent of a MSA's workers who identify their ancestry as English, German, Irish, Italian, Nordic, Other Western Europe, and Eastern Europe. The omitted category is the share of all others. Recall that we already include individual worker measures of race (including Asian), ethnicity, and foreign born (separately for citizen and non-citizen) from the CPS. As seen in line 8, introduction of the percent ancestry variables accounts for a substantial share of the labor market variation in $\mathrm{MJH}$, reducing the MAD from 0.615 to 0.47 . Given the regional differences in MJH, we expected that ancestry would be correlated with multiple job holding, but we did not anticipate such large effects. We find large positive effects from the share of workers whose ancestry are Nordic, German, English, and other Western Europe. The only negative ancestry coefficient was for the share Italian, but it was only slightly lower than the omitted ancestry group (i.e., those not in any of the above categories). We are confident in concluding that ancestry is strongly correlated with multiple job holding. We are less sure how to interpret these relationships and are reluctant to speculate on the causal pathways. Other scholars have found strong relationships between ancestry and economic performance across countries (Putterman and Weil 2010) and U.S. localities 
(e.g., Fulford, Petkov, and Schiantarelli 2015). The authors discuss pathways through which culture can affect economic outcomes.

In the analysis above, we did not control for the nine U.S. Census regions. If we add region dummies to our most dense specification, the unexplained mean deviation in multiple job holding declines little, from 0.47 in line 8 to 0.46 in line 9 . Of course, "region" is not really an explanation for why labor markets differ in multiple job holding. Rather, it is part of the puzzle we are trying to address. Had we introduced region prior to inclusion of the ancestry variables, the regional contribution would be substantive.

The final two measures we address are long-run employment growth and labor market churn. In line 10 we add a measure of log employment growth over the 1998-2014 period, calculated from the Quarterly Census of Employment and Wages (with county data aggregated to the MSA level). Once we control for all the other micro and MSA level variables, employment growth has little discernable effect on multiple job holding. As seen in line 10 of Table 3, the MAD measure remains at 0.46 when the employment growth measure is added.

We measure monthly labor market churn (turnover) based on our calculations using all rotation groups of the CPS from December 1997 through December 2014. We examine transitions of all individuals ages 18-65 from the current survey month and prior survey month for six rotation group pairs: 1-2, 2-3, 3-4, 5-6, 6-7, and 7-8 (we exclude 4-5 since there is an 8 month interval between these interviews). For each individual-month pair we measure whether individuals transitioned from not employed to employed (NE), from employed to not employed (EN), employed both months in the same job (EE-same job), employed both months but switched employers (EE-job switch), and not employed in either month (NN). Our measure of monthly churn (turnover) is calculated for each individual and then summed to an MSA measure. Included in the numerator are the number of hires plus the number of separations (NE counts as 1, EN as 1, EE-job switch as 2, and EE-same job and NN as 0), divided by 2 times MSA employment. This measure corresponds closely to the standard quarterly turnover measure used in the literature with establishment level data, wherein the numerator is the sum of hires plus separation and the denominator two times employment (e.g., Decker et al. 2014). Using establishment data, a worker leaving one establishment and joining another within a quarter is counted twice in the numerator, whereas those transitioning into and out of employment across quarters are each counted once.

As seen in line 11, the introduction of the turnover measure accounts for a modest amount of the dispersion in multiple job holding across labor markets, reducing the MAD measure from 0.46 to 0.44 . The MJH equation shows that multiple job holding is negatively related to the level of turnover. This result is supportive of our earlier argument that churn helps lubricate search and enables good matches, thus implying that good primary job matches mitigate the need for second jobs. The result is not inconsistent with the 
alternative argument that second jobs are frequently short-term (within a single quarter) and that high rates of churn are often associated with short-term jobs. But it is clear from our data that either second jobs differ in some ways with short-term primary jobs, or that this association is not sufficiently strong to produce a positive relationship between multiple job holding and labor market churn.

\section{Concluding Remarks}

A largely overlooked labor market outcome is that multiple job holding rates differ substantially across regions, states, and labor markets (MSAs). These differences display substantial fixity, appearing very similar over the 16 years span of our data. We document these persistent difference in regional and marketspecific multiple job holding across the U.S. and explore alternative explanations for the differences. Comparing the mean absolute deviation absent covariates ( 0.96 or roughly 1 percentage point) to the deviation following control for covariates (0.44) indicates that we have made substantive progress in understanding differences in $\mathrm{MJH}$ across labor markets.

Most important in explaining differences in MJH are worker characteristics, commute times, MSA ancestry shares, and, to a lesser extent, labor market churn. Although more than half the variation has been accounted for, substantial variation remains. Moreover, some of the covariates that "explain" the labor market (and regional) variation, in particular ancestry, generate their own set of questions as to the mechanism(s) through which they operate. That said, this research has clearly identified high commuting costs as an important deterrent of multiple job holding, largely accounting for the substantial differences in MJH associated with labor markets size. 


\section{References}

Abraham, Katherine G., John Haltiwanger, Kristin Sandusky, and James R. Spletzer. 2013. Exploring differences in employment between household and establishment Data. Journal of Labor Economics 31, no. 2, pt. 2:S129-S172.

Amuédo-Dorantes, Catalina, and Jean Kimmel. 2009. Moonlighting behavior over the business cycle. Economic Inquiry 47, no. 4:754-765.

Black, Dan A., Natalia Kolesnikova, and Lowell J. Taylor. 2014. Why do so few women work in New York (and so many in Minneapolis)? Labor supply of married women across US cities. Journal of Urban Economics 79: 59-71.

Conway, Karen and Jean Kimmel. 1998. Male labor supply estimates and the decision to moonlight. Labour Economics 5, no. 2: 135-166.

Conway Karen, and Jean Kimmel. 2001. Who Moonlights and why? Evidence from the SIPP. Industrial Relations 40, no. 1:89-120.

Decker, Ryan, John Haltiwanger, Ron S. Jarmin, and Javier. Miranda. 2014. The secular decline in business dynamism in the U.S. Unpublished manuscript, University of Maryland and U.S. Census Bureau.

Fulford, Scott L., Ivan Petkov, and Fabio Schiantarelli. 2015. Does it matter where you come from? Ancestry composition and economic performance of U.S. counties, 1850-2010. IZA Discussion Paper No. 9060, May.

Hall, Robert E. 1970. Why is the unemployment rate so high at full employment? Brookings Papers on Economic Activity? 70, no. 3:369-410.

Hipple, Steven F. 2010. Multiple jobholding during the 2000s. Monthly Labor Review (July): 21-32.

Hirsch, Barry T., Muhammad M. Husain, and John V. Winters. 2015. Multiple job holding, local labor markets, and the business cycle. Unpublished manuscript.

Hyatt, Henry R., and James R. Spletzer. 2013. The recent decline in employment dynamics. IZA Journal of Labor Economics 2, no. 5: 1-21.

Krishnan, Pramila. 1990. The economics of moonlighting: A double self-selection model. Review of Economics and Statistics 72, no. 2:361-367.

Krueger, Alan, Alexandre Mas, and Xiaotong Niu. 2014. The evolution of rotation group bias: Will the real unemployment rate please stand up? Industrial Relations Section W.P. 578, Princeton.

Lalé, Etienne. 2015. Multiple jobholding over the past two decades. Monthly Labor Review, April.

Molloy, Raven, Christopher L. Smith, and Abigail Wozniak. 2011. Internal migration in the United States. Journal of Economic Perspectives 25, no. 3: 173-196.

Molloy, Raven, Christopher L. Smith, and Abigail Wozniak. 2014. Declining migration within the U.S.: The role of the labor market. NBER Working Paper 20065.

Panos, Georgios, Konstantinos Pouliakas, and Alexandros Zangelidis. 2014. Multiple job holding, skill diversification, and mobility. Industrial Relations 53, no. 2: 223-272.

Partridge, Mark. 2002. Moonlighting in a high growth economy: Evidence from U.S. state-level data. Growth and Change 33, no 4: 424-452.

Paxson, Christina H., and Nachum Sicherman. 1996. The dynamics of dual job holding and job mobility. Journal of Labor Economics 14, no. 3: 357-393.

Putterman, Louis and David N. Weil. 2010. Post-1500 population flows and the long-run determinants of economic growth and inequality. Quarterly Journal of Economics 125, no. 4: 1627-1682.

Renna, Francesco, and Ronald L. Oaxaca. 2006. The economics of dual job holding: A job portfolio model of labor supply. IZA Discussion Paper No. 1915. 
Shishko Robert, and Bernard Rostkers. 1976. The economics of multiple job holding. American Economic Review 66, no. 3: 298-308.

Solon, Gary, Steven J. Haider, and Jeffrey M. Wooldridge. 2015. What are we weighting for? Journal of Human Resources 50, no. 2:301-316.

U.S. Bureau of Labor Statistics. 2015. Multiple job holding in states in 2014. Monthly Labor Review August, accessed at: http://www.bls.gov/opub/mlr/2015/article/multiple-jobholding-in-states-in-2014.htm. 


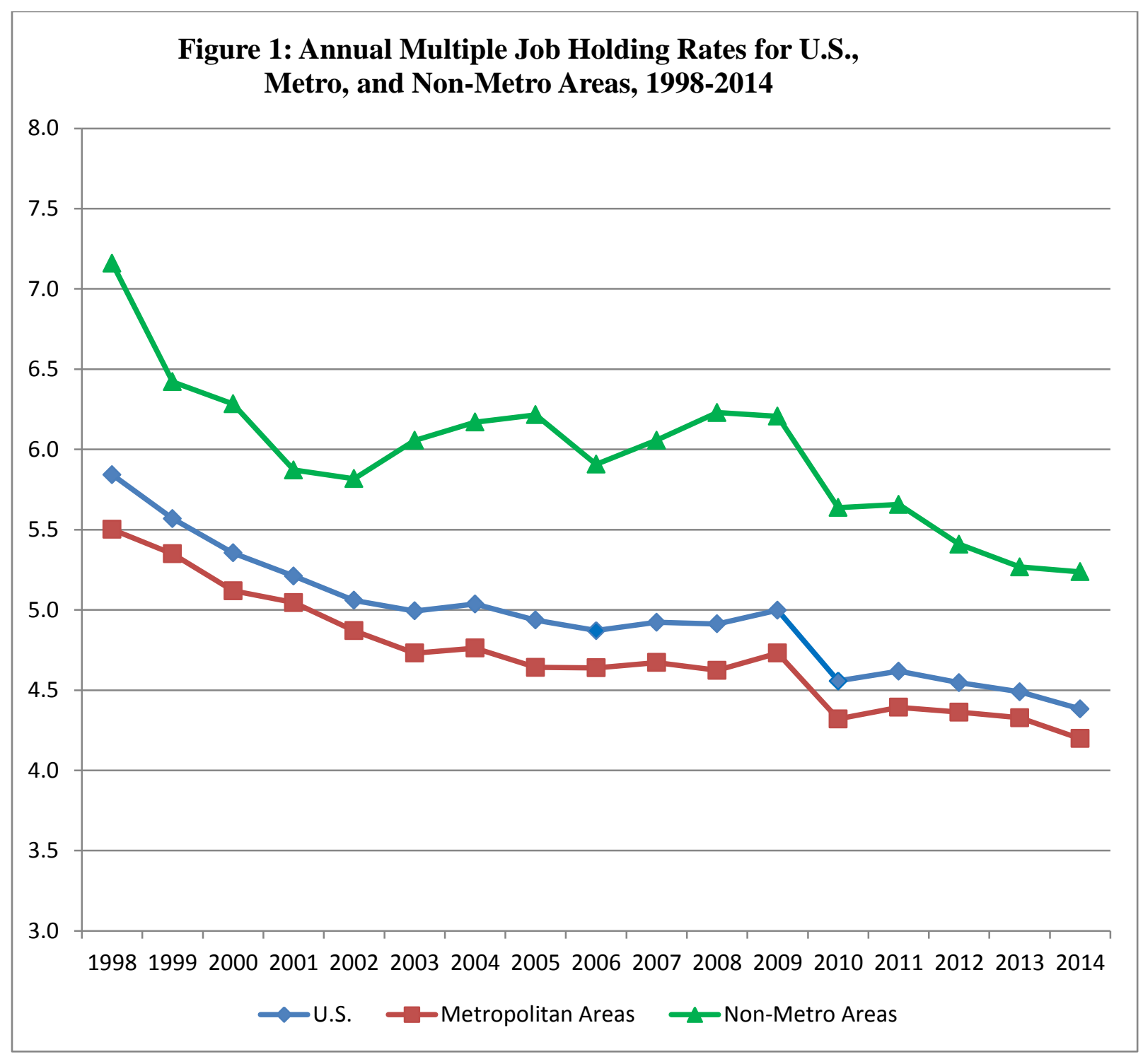


Figure 2: Quartile Rankings of Multiple Job Holding Rates among U.S. States 1998-1999

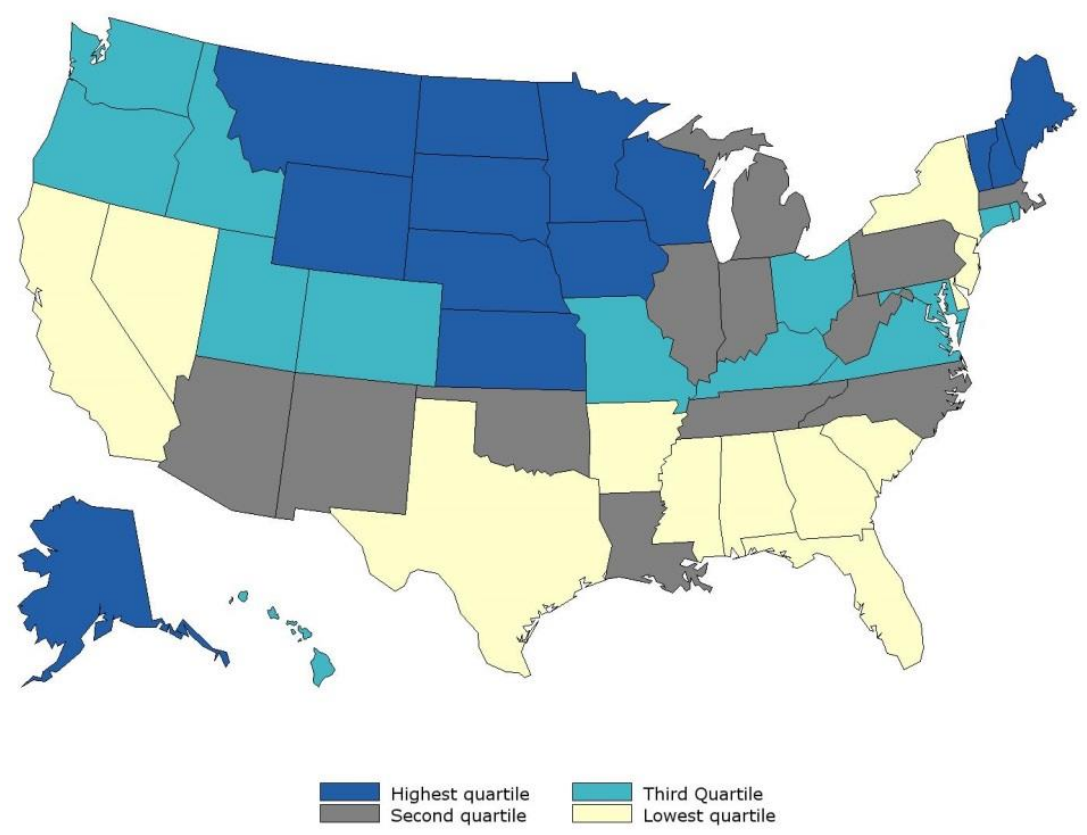

2013-2014

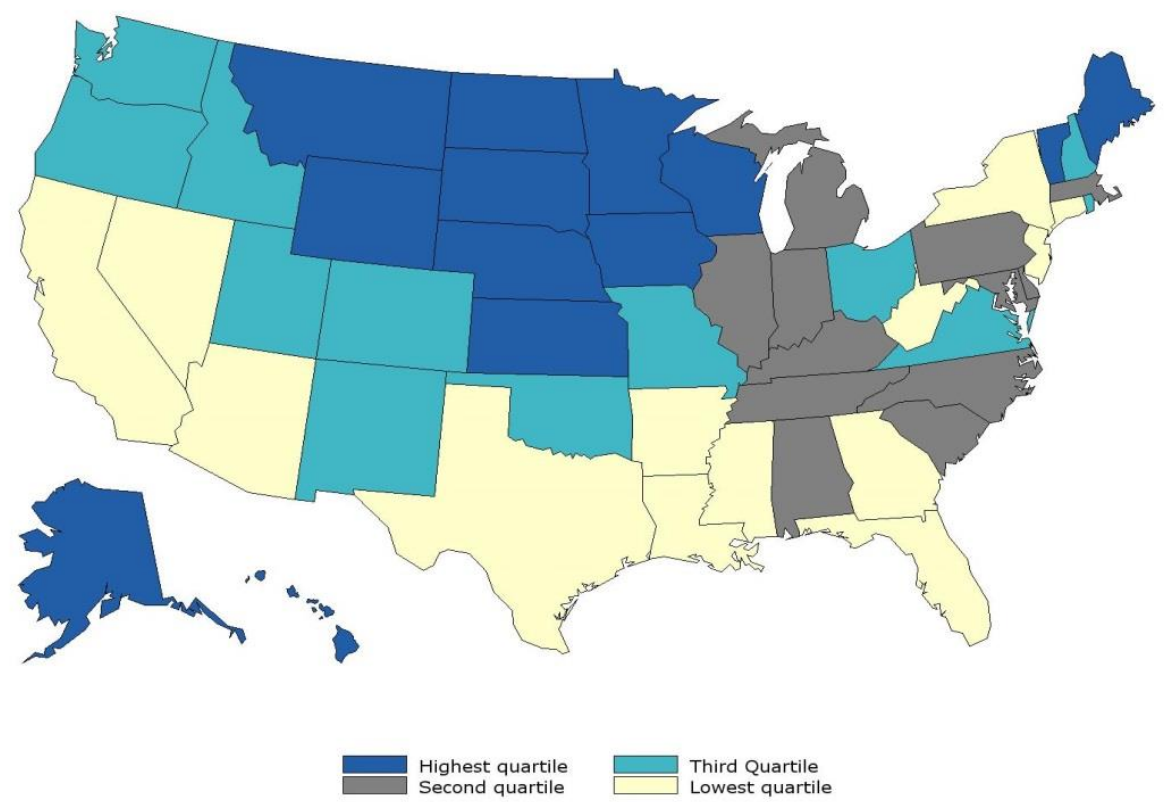


Figure 3: Scatterplots of 2013-2014 (y-axis) and 1998-1999 (x-axis) State Multiple Job Holding Rates and Rate Rankings

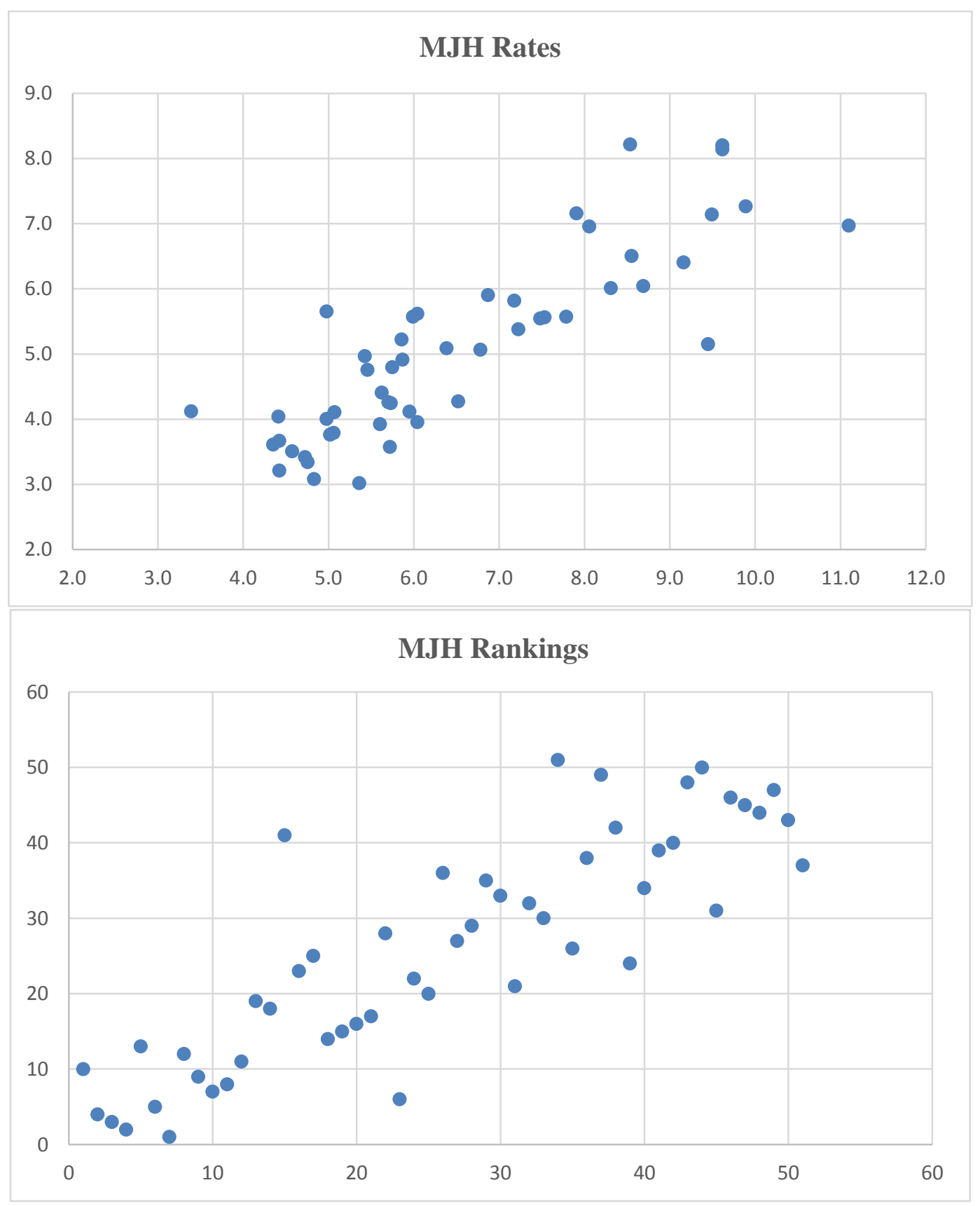


Figure 4: Scatterplot of 2012-2014 (y-axis) and 1998-2000 (x-axis) MSA Multiple Job Holding Rates

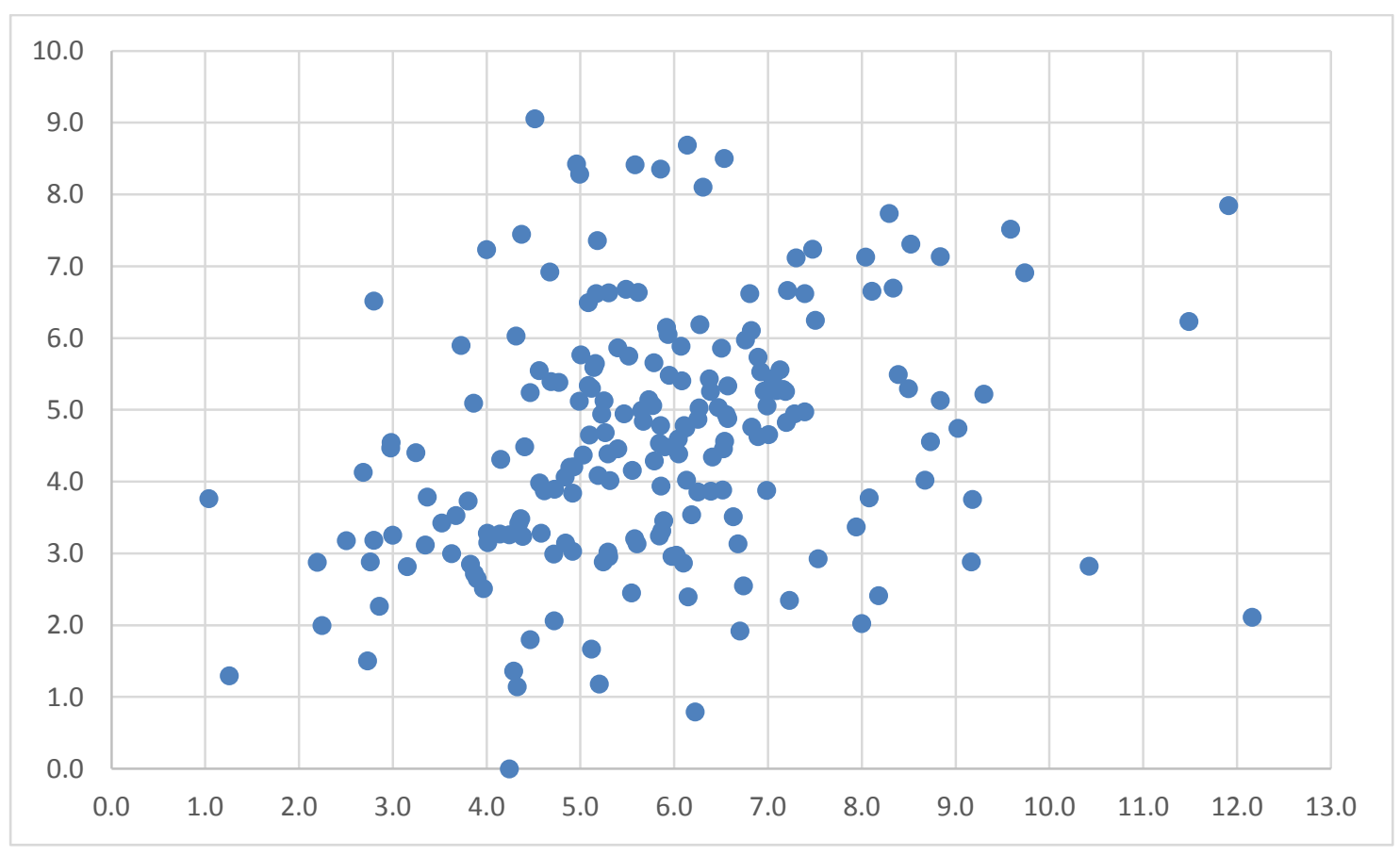


Table 1a: Highest 25 MSA Mean Multiple Job Holding Rates, 1998-2014

\begin{tabular}{clcc}
\hline & & Mean & \\
Rank & Metropolitan Area Name & MJH & Obs \\
\hline 1 & Madison, WI & 9.70 & 5,352 \\
2 & Sioux Falls, SD & 8.86 & 11,170 \\
3 & Fargo-Moorhead, ND-MN & 8.83 & 9,489 \\
4 & Burlington, VT & 8.39 & 12,668 \\
5 & Portland, ME & 8.18 & 12,058 \\
6 & Fort Collins-Loveland, CO & 7.81 & 3,300 \\
7 & Topeka, KS & 7.66 & 2,834 \\
8 & Provo-Orem, UT & 7.65 & 5,369 \\
9 & Eugene-Springfield, OR & 7.62 & 3,201 \\
10 & Minneapolis-St Paul-Bloomington, MN-WI & 7.59 & 37,510 \\
11 & Utica-Rome, NY & 7.57 & 2,011 \\
12 & Chico-Paradise, CA & 7.52 & 1,468 \\
13 & Duluth, MN-WI & 7.30 & 2,341 \\
14 & Omaha, NE-IA & 7.20 & 19,122 \\
15 & Green Bay, WI & 7.09 & 3,446 \\
16 & Kalamazoo-Battle Creek, MI & 7.08 & 2,639 \\
17 & Des Moines, IA & 6.97 & 9,750 \\
18 & Norwich-New London, CT-RI & 6.88 & 3,565 \\
19 & Lexington-Fayette, KY & 6.85 & 4,640 \\
20 & Honolulu, HI & 6.80 & 26,997 \\
21 & Rochester, NY & 6.72 & 7,593 \\
22 & Springfield, IL & 6.72 & 1,744 \\
23 & Johnstown, PA & 6.70 & 1,410 \\
24 & Santa Barbara-Santa Maria-Lompoc, CA & 6.68 & 1,899 \\
25 & Ann Arbor, MI & 6.67 & 3,612 \\
& & &
\end{tabular}

(Table $1 \mathrm{~b}$ continued on next page) 
Table 1b: Lowest 25 MSA Mean Multiple Job Holding Rates, 1998-2014

\begin{tabular}{clcc}
\hline & & Mean & \\
Rank & Metropolitan Area Name & MJH & Obs \\
\hline 178 & Gainesville, FL & 3.66 & 1,425 \\
179 & Orange County, CA & 3.66 & 83,348 \\
180 & Melbourne-Titusville-Palm Bay, FL & 3.60 & 3,443 \\
181 & Fort Myers-Cape Coral, FL & 3.60 & 3,327 \\
182 & Beaumont-Port Arthur, TX & 3.52 & 2,143 \\
183 & Riverside-San Bernardino, CA & 3.51 & 17,687 \\
184 & Houston-Baytown-Sugar Land, TX & 3.50 & 30,540 \\
185 & Lake Charles, LA & 3.47 & 1,488 \\
186 & Atlanta, GA & 3.46 & 29,251 \\
187 & Fresno, CA & 3.44 & 5,345 \\
188 & Port St. Lucie-Fort Pierce, FL & 3.38 & 2,027 \\
189 & New Orleans, LA & 3.37 & 7,665 \\
190 & Corpus Christi, TX & 3.33 & 2,226 \\
191 & Las Vegas-Paradise, NM & 3.31 & 30,294 \\
192 & New York-Northern New Jersey-Long Island, NY-NJ-PA & 3.26 & 125,737 \\
193 & Florence, AL & 3.23 & 1,582 \\
194 & Mobile, AL & 3.22 & 2,883 \\
195 & Augusta-Richmond County, GA-SC & 3.17 & 3,076 \\
196 & Bakersfield, CA & 3.17 & 3,886 \\
197 & Miami-Fort Lauderdale-Miami Beach, FL & 3.08 & 32,649 \\
198 & Ocala, FL & 2.86 & 1,300 \\
199 & El Paso, TX & 2.75 & 3,774 \\
200 & Visalia-Tulare-Porterville, CA & 2.75 & 1,875 \\
201 & Lakeland-Winter Haven, FL & 2.44 & 2,924 \\
202 & McAllen-Edinburg-Pharr, TX & 1.30 & 2,756 \\
\hline & & &
\end{tabular}


Table 2:

Multiple Job Holding Rates by Labor Market Size, 1998-2014

\begin{tabular}{|c|c|c|c|c|c|}
\hline MSA Size & Mean MJH & (1) & (2) & (3) & Obs \\
\hline non-urban & 6.0 & - & - & - & 690,688 \\
\hline $100-250 t$ & 5.5 & $\begin{array}{l}-0.51 \\
(0.36)\end{array}$ & $\begin{array}{l}-0.63 * \\
(0.30)\end{array}$ & $\begin{array}{l}-0.59 * * \\
(0.20)\end{array}$ & 152,162 \\
\hline $250-500 t$ & 5.3 & $\begin{array}{l}-0.68 * \\
(0.34)\end{array}$ & $\begin{array}{l}-0.86 * * \\
(0.28)\end{array}$ & $\begin{array}{l}-0.60 * * \\
(0.20)\end{array}$ & 191,506 \\
\hline $500 \mathrm{t}-1 \mathrm{~m}$ & 5.2 & $\begin{array}{l}-0.82 * \\
(0.36)\end{array}$ & $\begin{array}{l}-0.93 * * \\
(0.31)\end{array}$ & $\begin{array}{l}-0.82 * * \\
(0.22)\end{array}$ & 291,402 \\
\hline $1-2.5 m$ & 5.1 & $\begin{array}{l}-0.90 * * \\
(0.33)\end{array}$ & $\begin{array}{l}-0.95 * * \\
(0.28)\end{array}$ & $\begin{array}{l}-0.72 * * \\
(0.19)\end{array}$ & 485,463 \\
\hline $2.5-5 \mathrm{~m}$ & 4.7 & $\begin{array}{l}-1.31 * * \\
(0.44)\end{array}$ & $\begin{array}{l}-1.37 * * \\
(0.37)\end{array}$ & $\begin{array}{l}-1.48 * * \\
(0.24)\end{array}$ & 323,082 \\
\hline $5 \mathrm{~m}+$ & 3.9 & $\begin{array}{l}-2.11 * * \\
(0.38)\end{array}$ & $\begin{array}{l}-1.88 * * \\
(0.35)\end{array}$ & $\begin{array}{l}-1.50 * * \\
(0.27)\end{array}$ & 520,444 \\
\hline All U.S. & 5.0 & & & & $2,654,747$ \\
\hline
\end{tabular}

$*$ designates significance at the $.05, * *$ at the .01 level. Survey weights are used for both means and regression estimates. Model (1) MJH regression has no controls, thus providing mean differences in MJH relative to the omitted "non-urban" areas (small MSAs and rural areas not designated in the CPS). Model (2) includes detailed categorical variables for age, education, gender, race, ethnicity, marital status, children, foreign born, citizenship, hours worked in primary but not second job, public sector, union status, industry, occupation, year, and month. Model (3) adds regional dummies. 
Table 3: Mean Absolute Deviation (MAD) of Labor Market Multiple Job Holding Rates

\begin{tabular}{ccl}
\hline Model & MAD & Controls \\
\hline 1 & 0.955 & Year and month dummies \\
2 & 0.794 & 1 + sex, race/ethnicity, foreign-born, marital, child, age, educ dummies \\
3 & 0.738 & 2 + hours worked, log wage on $1^{\text {st }}$ job, public sector, union member \\
4 & 0.753 & $3+16$ occupation and 12 industry dummies \\
5 & 0.629 & 4 + mean MSA commute time \\
6 & 0.630 & 5 + city size dummies \\
7 & 0.615 & 6 + MSA mean hourly earnings, housing values, rental rates \\
8 & 0.472 & 7 + MSA percentage ancestry variables \\
9 & 0.460 & 8 + Census division (region) dummies \\
10 & 0.459 & $9+$ MSA Log employment growth between 1998 and 2014 \\
11 & 0.442 & 10 + MSA mean monthly churn (turnover), 1998-2014 \\
\hline
\end{tabular}

Mean absolute deviations (MAD) measure the dispersion in multiple job holding (MJH) rates across 202 MSAs over the years 1998-2014. MAD is calculated from the MSA fixed effects in each of the MJH weighted regression models designated above. The value .0096 in line 1 implies a 1 percentage point mean absolute deviation in $\mathrm{MJH}$. The mean $\mathrm{MJH}$ rate for the 202 MSAs over 1998-2014 is 0.050. The contribution of each set of variables is evaluated by the change in MAD. As discussed in the text, changes in MAD are not invariant to the order in which controls are introduced. 